\title{
Effect of Breeding Protocols and Reproductive Tract Score on Reproductive Performance of Dairy Heifers and Economic Outcome of Breeding Programs ${ }^{1}$
}

\author{
J. L. Stevenson, ${ }^{*}$ J. A. Rodrigues, ${ }^{*}$ F. A. Braga, ${ }^{*}$ S. Bitente, ${ }^{*}$ J. C. Dalton,† J. E. P. Santos,‡ \\ and R. C. Chebel ${ }^{\star 2,3}$ \\ ${ }^{*}$ Caine Veterinary Teaching Center, and \\ †Research and Extension Center, University of Idaho, Caldwell 83607 \\ $\ddagger$ Veterinary Medicine Teaching and Research Center, University of California-Davis, Tulare 93274
}

\begin{abstract}
The objectives of this study were to evaluate the effect of reproductive protocols and reproductive tract score on reproductive performance of dairy heifers and economic outcomes of breeding programs. Holstein heifers $(\mathrm{n}=534), 13 \pm 1 \mathrm{mo}$ of age, were randomly assigned to 1 of 4 reproductive protocols. On the day of enrollment (d 0), heifers were palpated per rectum and received a score according to the maturity of their reproductive tract $(1=$ prepubertal; $2=$ peripubertal; and $3=$ pubertal). Estrous detection-control heifers $(\mathrm{CON}, \mathrm{n}=146)$ received no treatment and were inseminated on detection of estrus for $28 \mathrm{~d}$. Prostaglandin $\mathrm{F}_{2 \alpha}$-treated heifers (PGED, $\mathrm{n}=137$ ) received 1 injection of $\mathrm{PGF}_{2 \alpha}$ on $\mathrm{d} 0$ and were inseminated on detection of estrus; heifers not inseminated by $\mathrm{d} 14$ received a second injection of $\mathrm{PGF}_{2 a}$ and were observed for estrus and artificial insemination (AI) for an additional $14 \mathrm{~d}$. Heifers enrolled in the estrous detection-timed AI (EDTAI, $\mathrm{n}=140$ ) treatment received a controlled internal drug-release (CIDR) insert on $\mathrm{d} 0$, and $7 \mathrm{~d}$ later, the CIDR was removed and all heifers received an injection of $\mathrm{PGF}_{2 a}$, heifers received $\mathrm{AI}$ on detection of estrus, and those not inseminated by $72 \mathrm{~h}$ after $\mathrm{PGF}_{2 \alpha}$ received an injection of $\mathrm{GnRH}$ concurrent with AI. Heifers in the GnRH-timed AI (GTAI, n $=111$ ) treatment received 1 injection of GnRH on d 0 , on d 6 heifers received a CIDR insert and injections of $\mathrm{GnRH}$ and $\mathrm{PGF}_{2 \alpha}$, on $\mathrm{d} 13$ the CIDR was removed and heifers received an injection of $\mathrm{PGF}_{2 a}$, and $48 \mathrm{~h}$
\end{abstract}

\footnotetext{
Received October 25, 2007.

Accepted March 14, 2008.

${ }^{1}$ We would like to thank Frank Hurtig from Merial Ltd. (Athens, GA) for providing Cystorelin and Frederico Moreira from Pfizer Animal Health (Kalamazoo, MI) for providing Lutalyse and controlled internal drug-release inserts. We would like to extend our gratitude to the owner and staff of Beranna Dairy (Caldwell, ID).

${ }^{2}$ Corresponding author: rchebel@vmtrc.ucdavis.edu

${ }^{3}$ Present address: Veterinary Medicine Cooperative Extension, University of California, Davis, 18830 Road 112, Tulare, CA 93274.
}

later all heifers received an injection of $\mathrm{GnRH}$ and AI. Pregnancy was diagnosed at $32 \pm 3$ and $62 \pm 3 \mathrm{~d}$ after AI. Cost of reproductive protocols and their economic outcomes were calculated for a $28 \mathrm{~d}$ period beginning at enrollment. Heifers in the PGED treatment were inseminated at a faster rate than $\mathrm{CON}$ heifers. A smaller proportion of prepubertal and peripubertal heifers were inseminated within $14 \mathrm{~d}$ of enrollment compared with pubertal heifers. Pregnancy per AI of CON and PGED heifers was greater compared with EDTAI and GTAI heifers. Proportion of GTAI heifers pregnant at the end of the 28-d breeding program was or tended to be smaller compared with PGED and CON heifers, respectively. Heifers in the CON and PGED treatments had the smallest cost per pregnancy followed by heifers in the EDTAI and GTAI treatments, respectively. When different scenarios were evaluated, however, the mean cost per pregnancy was smallest for PGED heifers. Cost per pregnancy generated was greatest for prepubertal heifers, whereas pubertal heifers had the smallest cost per pregnancy generated. Treatment of dairy heifers with $\mathrm{PGF}_{2 a}$ every $14 \mathrm{~d}$ until insemination and pregnancy results in the best economic outcomes, and screening heifers according to RTS may prove beneficial to identify heifers that may not be pubertal and would have compromised reproductive and economic performance in a breeding program.

Key words: reproductive protocol, economic outcome, dairy heifer

\section{INTRODUCTION}

Productive life, milk yield, reproductive performance, and health of primiparous Holstein cows is closely related to their age at first calving and weight after calving (Keown and Everett, 1986; Gabler et al., 2000; Ettema and Santos, 2004). Only $2.7 \%$ of dairy farms in the United States, however, achieve the recommended target of $\leq 24$ mo of age at calving and $\geq 560 \mathrm{~kg}$ of live weight immediately after calving (Losinger and Heinrichs, 1997), which could result in economic losses 
to the dairy herd. Furthermore, following the costs of feeding the lactating herd, raising replacement heifers is the second largest expense in dairy operations (Gabler et al., 2000).

The most commonly used reproductive protocol for dairy heifers is insemination on detection of spontaneously displayed estrus. The proportion of heifers pregnant following insemination on detection of spontaneous estrus ranges from 50 to $76 \%$ (Jochle et al., 1982; Schilling et al., 1982; Tanabe and Hann, 1984). This reproductive protocol, however, requires daily observation for signs of estrus and may result in extended interval from puberty to pregnancy depending on estrous detection efficiency and accuracy.

Treatment of heifers with $\mathrm{PGF}_{2 \alpha}$ at random stages of the estrous cycle resulted in 60 to $70 \%$ of animals displaying estrus 2 to $11 \mathrm{~d}$ after treatment (Tanabe and Hann, 1984; Kaim et al., 1990; Chebel et al., 2007). Furthermore, when heifers were treated with 2 injections of $\mathrm{PGF}_{2 \alpha} 11 \mathrm{~d}$ apart, the proportion of animals displaying estrus and inseminated within $7 \mathrm{~d}$ after the last injection was $100 \%$ (Jochle et al., 1982). The fertility of dairy heifers synchronized with $\mathrm{PGF}_{2 \alpha}$ was comparable to that of heifers not synchronized (Kaim et al., 1990).

The treatment of heifers with intravaginal progesterone inserts and $\mathrm{PGF}_{2 \alpha}$ has resulted in tighter estrous synchrony compared with heifers synchronized with 1 injection of $\mathrm{PGF}_{2 \alpha}$ alone, with approximately 84 and $57 \%$ of heifers displaying signs of estrus during the first $3 \mathrm{~d}$ after treatment, respectively (Lucy et al., 2001). In this same study, although the proportion of heifers that became pregnant after a 30-d breeding program was not affected by reproductive protocols, heifers synchronized with intravaginal progesterone inserts and $\mathrm{PGF}_{2 \alpha}$ became pregnant at a faster rate than those synchronized with $\mathrm{PGF}_{2 \alpha}$ alone (Lucy et al., 2001).

Dairy heifers inseminated at a fixed time after the completion of the Ovsynch protocol have reduced fertility compared with those inseminated on detection of estrus (Pursley et al., 1997; Tenhagen et al., 2005). The proportion of lactating dairy cows that become pregnant after the Ovsynch protocol is dependent on the proportion of cows that ovulate in response to the first GnRH injection (Vasconcelos et al., 1999; Chebel et al., 2006). Presynchronization of dairy heifers with $\mathrm{GnRH}$ $6 \mathrm{~d}$ before the initiation of an ovulation synchronization protocol resulted in increased ovulation in response to the first GnRH injection of the protocol (Stevenson et al., 2006). Furthermore, growth of the ovulatory follicle of beef cows and dairy heifers under low concentrations of progesterone resulted in a reduced interval from
$\mathrm{PGF}_{2 \alpha}$ treatment to estrus and ovulation (Stegner et al., 2004; Stevenson et al., 2006).

Reproductive tract scoring (RTS) is a method of evaluating pubertal status of heifers that has been used in the beef industry. The RTS is performed by manual palpation per rectum of the uterine horns and ovaries to evaluate reproductive tract maturity according to structures present in the ovaries and tonicity of the uterine horns (Andersen et al., 1991). The level of agreement between classification of heifers as prepubertal or pubertal according to the RTS system compared with serum progesterone and ultrasonography of the ovaries is relatively high (Rosenkrans and Hardin, 2003). Therefore, it is possible that the RTS system could be implemented in dairy operations to identify heifers that are prepubertal.

Hypotheses of the present study were that 1) synchronization of estrus with $\mathrm{PGF}_{2 \mathrm{a}}$ would result in a faster insemination rate with no detrimental effect to fertility compared with no synchronization; 2) use of intravaginal progesterone inserts would result in an increased proportion of heifers pregnant within a $28-d$ period and improved economic outcome compared with insemination on detection of spontaneous or $\mathrm{PGF}_{2 \alpha^{-}}$ induced estrus; 3 ) use of a new fixed-time AI protocol would result in an acceptable proportion of heifers pregnant within $28 \mathrm{~d}$ after the initiation of the breeding program; and 4) classification of heifers according to RTS is useful in predicting their fertility. Therefore, objectives of the present study were to compare the reproductive efficiency and economic outcome of different reproductive protocols for dairy heifers during a 28-d breeding period and to evaluate the reproductive performance of heifers with different RTS at the initiation of the breeding period.

\section{MATERIALS AND METHODS}

All procedures were approved by the University of Idaho's Animal Care and Use Committee.

\section{Animals and Diet}

Holstein heifers $(\mathrm{n}=599), 13 \pm 1$ mo of age, from a commercial dairy located in the Treasure Valley of Idaho were used in this experiment. Heifers were housed in open lots and were fed a diet as a TMR once a day. The diet was based on wheat silage, alfalfa hay, soybean meal, steam-rolled corn, whole cottonseed, and a mineral and vitamin supplement and was designed to exceed the nutritional requirements of Holstein heifers weighing $360 \mathrm{~kg}$ and gaining $0.8 \mathrm{~kg} / \mathrm{d}$ (NRC, 2001). 

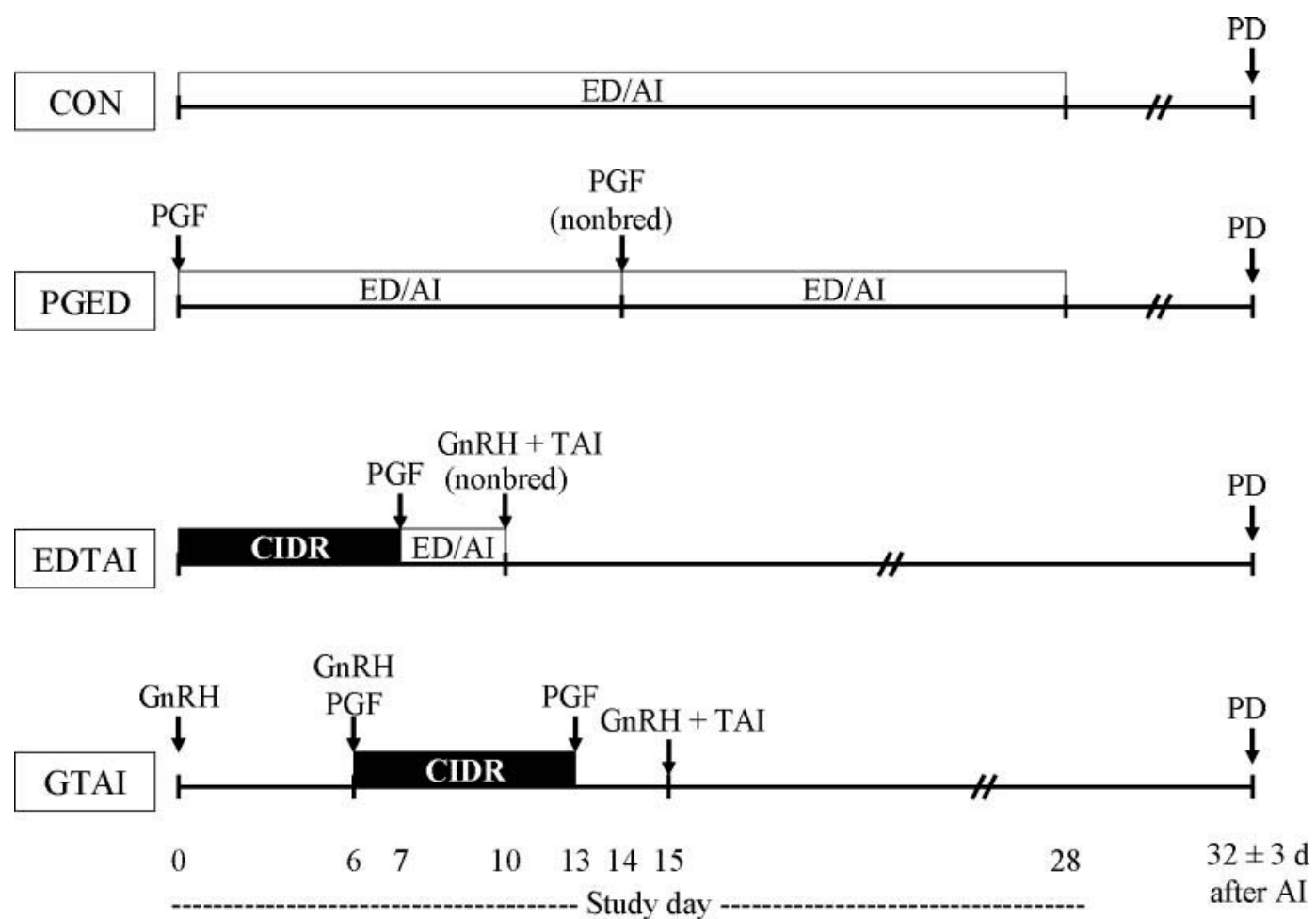

Figure 1. Diagram of activities. CIDR = controlled internal drug-release insert containing $1.38 \mathrm{~g}$ of progesterone (Eazi-Breed CIDR insert, Pfizer Animal Health, Kalamazoo, MI); ED = estrous detection; GnRH = $100 \mu \mathrm{g}$ of GnRH (gonadorelin diacetate tetrahydrate, Cystorelin; Merial Ltd., Athens, GA); PGF = $25 \mathrm{mg}$ of $\mathrm{PGF}_{2 \mathrm{a}}$ (Lutalyse Sterile Solution, dinoprost tromethamine sterile solution, Pfizer Animal Health); $\mathrm{PD}=$ pregnancy diagnosis; $\mathrm{TAI}=$ fixed-time $\mathrm{AI}$.

\section{Treatments}

Heifers were enrolled in this study in 4 replicates from September 2005 to March 2006. Therefore, bimonthly, 160 heifers were randomly assigned to 1 of 4 reproductive protocols (Figure 1). Heifers enrolled in the estrous detection-control $(\mathbf{C O N}, \mathrm{n}=152)$ treatment received no treatment and were inseminated on detection of estrus for $28 \mathrm{~d}$ (study d $28=$ end of the breeding period). Prostaglandin $\mathrm{F}_{2 \alpha}$-treated heifers (PGED, $\mathrm{n}$ $=150)$ received 1 injection of $25 \mathrm{mg}$ of $\mathrm{PGF}_{2 \alpha}(5 \mathrm{~mL}$, Lutalyse Sterile Solution, dinoprost tromethramine sterile solution, Pfizer Animal Health, Kalamazoo, MI) on study d 0 (day of enrollment) and were inseminated on detection of estrus; after $14 \mathrm{~d}$, heifers not inseminated received a second injection of $\mathrm{PGF}_{2 \alpha}$ and were inseminated on detection of estrus for an additional $14 \mathrm{~d}$. Heifers assigned to the estrous detection-timed AI (EDTAI, $\mathrm{n}=149$ ) treatment received a controlled internal drug-release (CIDR) insert (1.38 g of progesterone, Eazi-Breed CIDR insert, Pfizer Animal Health) on study d $0,7 \mathrm{~d}$ later the CIDR insert was removed and all heifers received an injection of $25 \mathrm{mg}$ of $\mathrm{PGF}_{2 \mathrm{a}}$; heifers were then inseminated on detection of estrus, and those not inseminated by $72 \mathrm{~h}$ after CIDR removal received an injection of $100 \mu \mathrm{g}$ of $\mathrm{GnRH}(2 \mathrm{~mL}$, gonad- orelin diacetate tetrahydrate, Cystorelin, Merial Ltd., Athens, GA) concurrent with timed AI (TAI). Finally, heifers enrolled in the GnRH-timed AI (GTAI, $\mathrm{n}=148$ ) treatment were presynchronized with 1 injection of $100 \mu \mathrm{g}$ of GnRH on study d 0; on study d 6 all heifers received a CIDR insert, an injection of $100 \mu \mathrm{g}$ of $\mathrm{GnRH}$, and an injection of $25 \mathrm{mg}$ of $\mathrm{PGF}_{2 \mathrm{a}}$; at CIDR removal (study d 13) all heifers received an injection of $25 \mathrm{mg}$ of $\mathrm{PGF}_{2 a}$, and $48 \mathrm{~h}$ after CIDR removal (study d 15) all heifers received an injection of $100 \mu \mathrm{g}$ of $\mathrm{GnRH}$ concurrent with TAI.

\section{Body Condition and Reproductive Tract Scores}

At enrollment heifers were assigned a BCS (1 = emaciated to $5=$ obese) according to Ferguson et al. (1994) by 1 technician. For purposes of statistical analysis, heifers were classified as having low (BCS $\leq 3.0$ ), moderate $(\mathrm{BCS}=3.25$ to 3.75$)$, and high $(\mathrm{BCS} \geq 4.0) \mathrm{BCS}$. In addition, heifers were manually palpated per rectum, and their reproductive tracts were scored. Scoring of the reproductive tract was adapted from Andersen et al. (1991) and was performed by 1 technician. Heifers that had toneless uterine horns and follicles $<8 \mathrm{~mm}$ in diameter received a score of 1 (prepubertal). Those heifers that had uterine horns with slight tone and follicles 
Table 1. Cost, range of cost, and increment of cost of items included in the evaluation of economic outcomes

\begin{tabular}{|c|c|c|c|}
\hline Item & Cost $(\$)$ & Range (\$) & Increment (\$) \\
\hline GnRH, ${ }^{1}$ per dose & 1.65 & 1.50 to 4.50 & 0.50 \\
\hline $\mathrm{PGF}_{2 \mathrm{a}}, 2$ per dose & 2.50 & 1.50 to 4.50 & 0.50 \\
\hline CIDR inserts, ${ }^{3}$ per insert & 8.00 & 5.50 to 10.50 & 1.00 \\
\hline Labor, per hour & 10.00 & 6.5 to 18.50 & 2.00 \\
\hline Daily rearing cost, per heifer per day & 1.65 & 0.75 to 2.25 & 0.25 \\
\hline
\end{tabular}

between 8 and $10 \mathrm{~mm}$ in diameter received a score of 2 (peripubertal). Heifers with toned uterine horns and follicles $>10 \mathrm{~mm}$ in diameter and those with a palpable corpus luteum (CL) received a reproductive tract score of 3 (pubertal).

\section{Detection of Estrus and Insemination}

All heifers were observed daily, in the morning, for estrus based on tail paint (Tail Paint Animal Marker, FiL, Mount Maunganui, New Zealand). Control and PGED heifers were inseminated on detection of estrus throughout the study period, whereas EDTAI heifers were inseminated on detection of estrus from study d 7 to 10. Those heifers in the EDTAI treatment not inseminated by study d 10 received fixed-time AI concurrent with a GnRH injection. All GTAI heifers were inseminated at a fixed time after the completion of the synchronization protocol. The number of EDTAI and GTAI heifers that displayed estrus before and at the time of TAI was recorded. One technician inseminated the heifers in the first 2 replicates, and a second technician inseminated heifers in the last 2 replicates. Therefore, for purposes of statistical analyses, the AI technician was recorded.

\section{Pregnancy Diagnosis and Fetal Sexing}

Pregnancy was diagnosed at $32 \pm 3 \mathrm{~d}$ after AI by ultrasonography of the uterus and its contents and was characterized by visualization of fluid, an embryo, and heart beat. A subsample of heifers $(n=178)$ diagnosed pregnant at $32 \pm 3 \mathrm{~d}$ after $\mathrm{AI}$ was reexamined approximately $30 \mathrm{~d}$ later ( $62 \pm 3 \mathrm{~d}$ after AI) by ultrasonography for evaluation of fetal survival and determination of fetal sex.

\section{Calculation of Economic Outcomes and Scenarios}

Data used for evaluation of economic outcomes of the reproductive protocols were based on actual data from the dairy, which is depicted in Table 1. Briefly, the reproductive protocol costs were calculated based on costs of drugs, labor costs for treatment of animals, and labor costs for detection of estrus. The approximate time spent to identify and treat heifers with injectable drugs was $1 \mathrm{~min}$, to introduce CIDR inserts was $2 \mathrm{~min}$, and to remove CIDR inserts was $1 \mathrm{~min}$. According to observations in the dairy, it was estimated that the average time spent by AI technicians for detection of estrus was $15 \mathrm{~s} /$ heifer per day. For purposes of calculation of the cost of reproductive protocols, it was assumed that the number of days that heifers in the CON and PGED treatments were observed for estrus was 28, whereas EDTAI heifers were observed for $3 \mathrm{~d}$, and GTAI heifers were not observed for estrus, because they were inseminated at a fixed time. The rearing cost during the study period was calculated based on daily maintenance cost per heifer multiplied by the number of days from enrollment in the study to pregnancy or to the end of the study period for heifers that did not become pregnant. The costs of the breeding programs (CBP) were calculated by adding the reproductive protocol cost and the rearing cost. Finally, the mean cost per pregnancy generated (CPG) for each treatment was calculated as follows:

$$
\begin{aligned}
\mathrm{CPG}= & \frac{\text { (total } \mathrm{CBP} \text { of nonpregnant heifers })}{(\text { number of pregnant heifers })} \\
& +(\mathrm{CBP} \text { of individual heifers }) .
\end{aligned}
$$

To evaluate the economic outcomes of the different reproductive protocols in different scenarios, price assumptions regarding cost of drugs, labor, and rearing heifers were made. The price ranges used were determined based on reports from agricultural magazines and producers; we extrapolated the range obtained from these reports, however, to evaluate situations that seemed realistic (Table 1). As the price of one item varied, the price of the other items remained the same, 
such that a total of 35 different scenarios were evaluated.

\section{Study Design and Statistical Analyses}

The experiment was a completely randomized design consisting of 4 treatments. Randomization was done before arrival in the dairy by the drawing of papers with the name of each treatment. At the dairy, heifers were assigned sequentially to 1 of the 4 reproductive protocols (CON, PGED, EDTAI, and GTAI) according to the allocation sheet. The original number of experimental units per treatment (140/treatment) was expected to provide enough replicates to detect statistical significance with a $10 \%$ unit difference in proportion of heifers pregnant at the end of the breeding program, when it ranges from 57 to $67 \%(\alpha=0.05 ; \beta=0.20)$ according to a 1-tailed test.

Dichotomous outcomes such as proportion of heifers inseminated by study d 14 and 28, proportion of heifers pregnant after AI, proportion of heifers pregnant at the end of the study, proportion of heifers experiencing pregnancy loss, and proportion of heifers bearing a female fetus were analyzed by logistic regression using the LOGISTIC procedure of SAS (SAS Institute Inc., Cary, NC) with a model that included treatment (CON, PGED, EDTAI, or GTAI). Other explanatory variables such as reproductive tract score (prepubertal, peripubertal, or pubertal), BCS, and AI technician (A or B) were only included in the model when their effect on the outcome was $P \leq 0.15$ according to univariate analyses. To determine the effect of estrous expression at the time of $\mathrm{AI}$ on proportion of heifers that became pregnant in the EDTAI and GTAI treatments, the model also included whether or not heifers displayed signs of estrus (estrus and no estrus) at the time of AI. The final logistic regression model removed variables by a backward elimination based on Wald's statistics criterion if the significance was greater than 0.15 . When independent variables had more than $1 \mathrm{df}$, the contrast statement of the LOGISTIC procedure was used to compare the levels of the independent variables.

Continuous distributed data such as the interval between enrollment and insemination and between enrollment and pregnancy, reproductive protocol cost, rearing cost, cost of the breeding program, and cost per pregnancy generated were analyzed by ANOVA using the GLM procedure of SAS, and data are presented as mean \pm SEM. The model included reproductive protocol. Reproductive tract score, BCS, and AI technician were only included in the model when their effect on the outcome was $P \leq 0.15$ according to univariate analyses.

The hazard ratios for insemination or pregnancy after enrollment in the study for heifers in the CON and PGED treatments were analyzed by the Cox proportional hazards regression using the TPHREG procedure of SAS. The model included reproductive protocol (CON or PGED). As described above, reproductive tract score, BCS, and $\mathrm{AI}$ technician were only included in the model when their effect on the outcome was $P \leq 0.15$ according to univariate analyses. The final logistic regression model removed variables by a backward elimination based on Wald's statistics criterion if $P>0.15$. Explanatory variables identified as affecting the hazard ratio for insemination or pregnancy were further analyzed for their effect on the interval between the initiation of the breeding program and AI or pregnancy by survival analysis using the product limit method of the Kaplan-Meier model by the LIFETEST procedure of SAS.

\section{RESULTS}

Twenty-four GTAI heifers were randomly selected for intensive ultrasonographic examination of the ovaries and blood sample collections and were not used in the statistical analyses of this experiment. This was done by randomly selecting 6 heifers from the GTAI treatment from each of the 4 replicates. Forty-one heifers $(\mathrm{CON}=6, \mathrm{PGED}=13, \mathrm{EDTAI}=9, \mathrm{GTAI}=13)$ were moved to a pen with bulls before the end of the study and were also removed. Therefore, 534 heifers were used for statistical analyses $(\mathrm{CON}=146$, PGED $=137$, EDTAI $=140$, GTAI $=111)$. The average BCS $(3.49 \pm 0.33)$ at enrollment was not $(P=0.66)$ different among treatments. The frequency distribution of heifers according to RTS, however, was $(P<0.01)$ different among treatment, and a smaller proportion of EDTAI heifers was pubertal (CON $=76.0$, PGED $=69.3$, EDTAI $=57.9$, GTAI $=74.8 \%$ ). Interestingly, however, BCS at enrollment did not $(P=0.99)$ affect the proportion of prepubertal, peripubertal, and pubertal heifers, respectively (low $=8.3,19.4$, and $72.2 \%$; moderate $=$ $8.3,19.8$, and $72.0 \%$; high $=6.1,18.4$, and $75.5 \%$ ).

\section{Patterns of Estrous Expression and Estrous Detection Rate}

Among heifers receiving AI, PGED and EDTAI heifers had the shortest $(P<0.01)$ interval from enrollment to AI followed by CON and GTAI heifers, respectively $(\mathrm{CON}=12.1 \pm 0.6, \mathrm{PGED}=8.7 \pm 0.5, \mathrm{EDTAI}=9.7$ \pm 0.5$, GTAI $=15.0 \pm 0.6 \mathrm{~d})$. Reproductive tract score affected $(P<0.01)$ the interval from enrollment to AI and pubertal heifers had $(P<0.01)$ and tended to have $(P=0.07)$ shorter intervals than prepubertal and peripubertal heifers, respectively, and peripubertal heifers had $(P=0.01)$ shorter intervals than prepubertal 


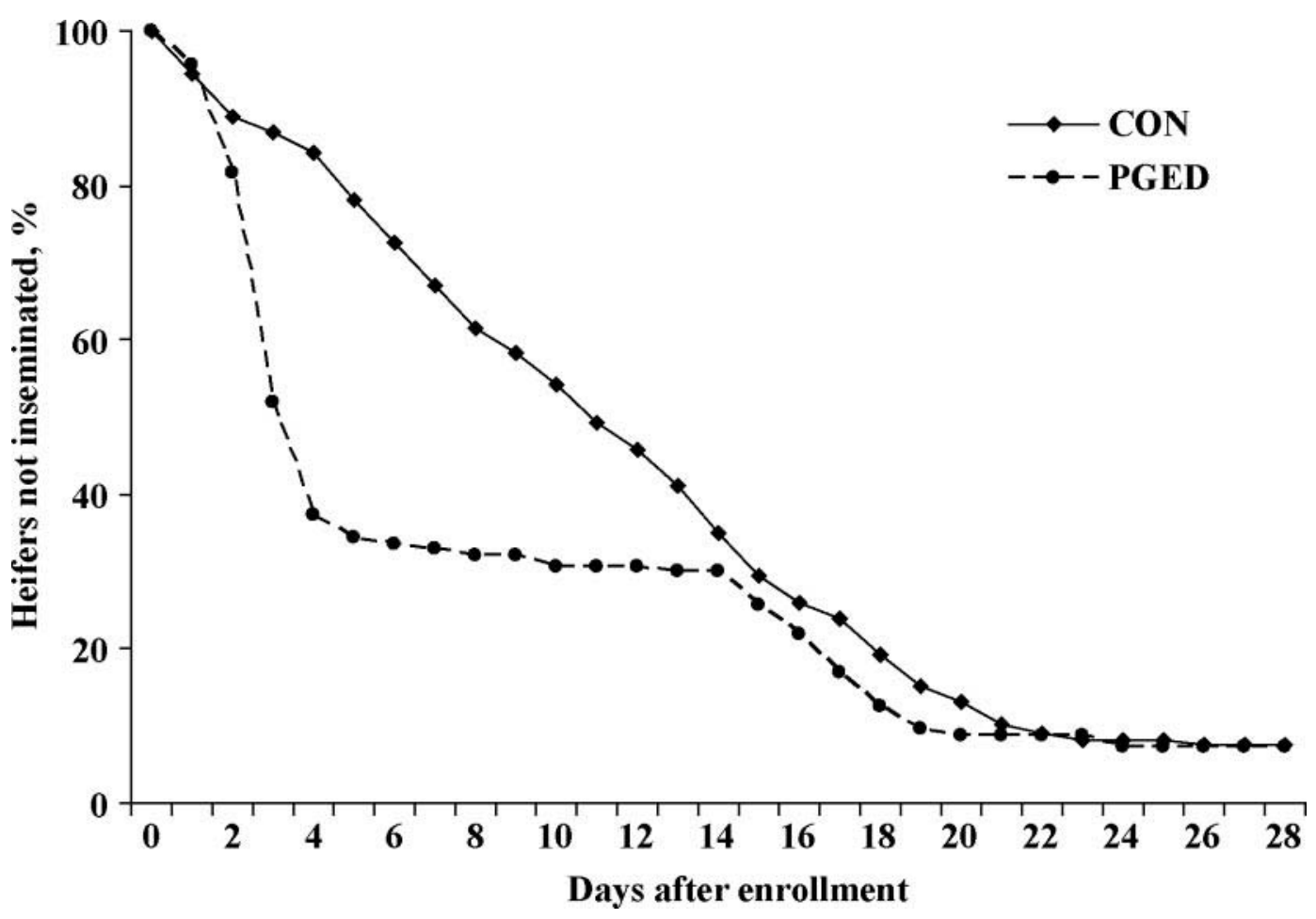

Figure 2. Rate at which CON (control) and PGED ( $\mathrm{PGF}_{2 \alpha}$-treated) heifers were inseminated after enrollment. Level of significance according the Cox proportional hazards ratio analysis was $P<0.01$ and according to the survival analysis was $P<0.01$. Mean ( \pm SEM) and median days from enrollment to $\mathrm{AI}$ : $\mathrm{CON}=11.88 \pm 0.59$ and $11.0 \mathrm{~d}$, respectively, and PGED $=8.04 \pm 0.65$ and $4.0 \mathrm{~d}$, respectively.

heifers (prepubertal $=13.1 \pm 0.7$, peripubertal $=11.0 \pm$ 0.4 , pubertal $=10.1 \pm 0.2 \mathrm{~d})$. The interaction $(P<0.01)$ between reproductive protocol and RTS affected the interval from enrollment to AI, because peripubertal and pubertal CON heifers had shorter intervals than prepubertal $\mathrm{CON}$ heifers (prepubertal $=15.6 \pm 1.5$, peripubertal $=10.3 \pm 0.9$, pubertal $=10.5 \pm 0.4 \mathrm{~d}$ ), whereas within the PGED treatment, pubertal heifers had the shortest interval and prepubertal heifers had the longest (prepubertal $=11.8 \pm 1.5$, peripubertal $=$ $9.0 \pm 0.8$, pubertal $=5.4 \pm 0.5 \mathrm{~d}$ ). For those heifers that were inseminated, the $\mathrm{AI}$ technician $\operatorname{did} \operatorname{not}(P=0.90)$ affect the interval from enrollment to $\mathrm{AI}(\mathrm{A}=10.4 \pm$ $0.3, \mathrm{~B}=10.3 \pm 0.4 \mathrm{~d}$ ).

When comparing CON and PGED heifers, it was observed that PGED heifers were inseminated at a faster rate $(P<0.01)$ than $\mathrm{CON}$ heifers (Figure 2$)$. Actually, within $3 \mathrm{~d}$ of enrollment, a greater $(P<0.01)$ proportion of PGED heifers received AI compared with CON heifers $(\mathrm{CON}=13.0, \mathrm{PGED}=48.2 \%)$. Despite the faster insemination rate of PGED heifers, the proportion of heifers inseminated by $14(\mathrm{CON}=65.1, \mathrm{PGED}=70.1 \%$; $P=0.35)$ and $28(\mathrm{CON}=92.5, \mathrm{PGED}=92.7 \% ; P=0.97)$ $\mathrm{d}$ after enrollment was not different between $\mathrm{CON}$ and PGED treatments. Reproductive tract score did not ( $P$ $=0.38$ ) affect the rate at which CON and PGED heifers were inseminated. Reproductive tract score, however, affected $(P<0.01)$ the proportion of heifers inseminated within $14 \mathrm{~d}$ after enrollment, because the proportion of pubertal heifers inseminated was $(P<0.01)$ and tended $(P=0.08)$ to be greater compared with peripubertal and prepubertal heifers, respectively (prepubertal $=35.3$, peripubertal $=61.7$, pubertal $=71.8 \%$ ). There was a tendency $(P=0.08)$ for the interaction between the reproductive protocol and RTS to affect the proportion of heifers inseminated within $14 \mathrm{~d}$ after enrollment (Figure 3$)$. Reproductive tract score did not $(P=0.39)$ affect the proportion of CON and PGED heifers inseminated $28 \mathrm{~d}$ after enrollment (prepubertal $=94.1$, peripubertal $=96.7$, pubertal $=91.3 \%$ ). The rate at which heifers in the CON and PGED treatments were inseminated was $(P<0.01)$ affected by AI technician (mean \pm SEM days from enrollment to $\mathrm{AI}-\mathrm{A}=8.4 \pm 0.5, \mathrm{~B}=11.9 \pm$ $0.7 \mathrm{~d})$, and technician A inseminated greater $(P<0.01)$ proportion of heifers within $14(\mathrm{~A}=76.5, \mathrm{~B}=57.5 \%)$ and $28(\mathrm{~A}=98.7, \mathrm{~B}=85.8 \%) \mathrm{d}$ than technician $\mathrm{B}$.

A greater $(P<0.01)$ proportion of EDTAI heifers displayed estrus at the time of insemination compared with GTAI heifers (86.4 and 74.3\%). The proportion of heifers displaying estrus within $48 \mathrm{~h}$ of CIDR removal, however, was smaller $(P<0.01)$ for the EDTAI treatment than the GTAI treatment (35.0 and $74.3 \%)$. The 


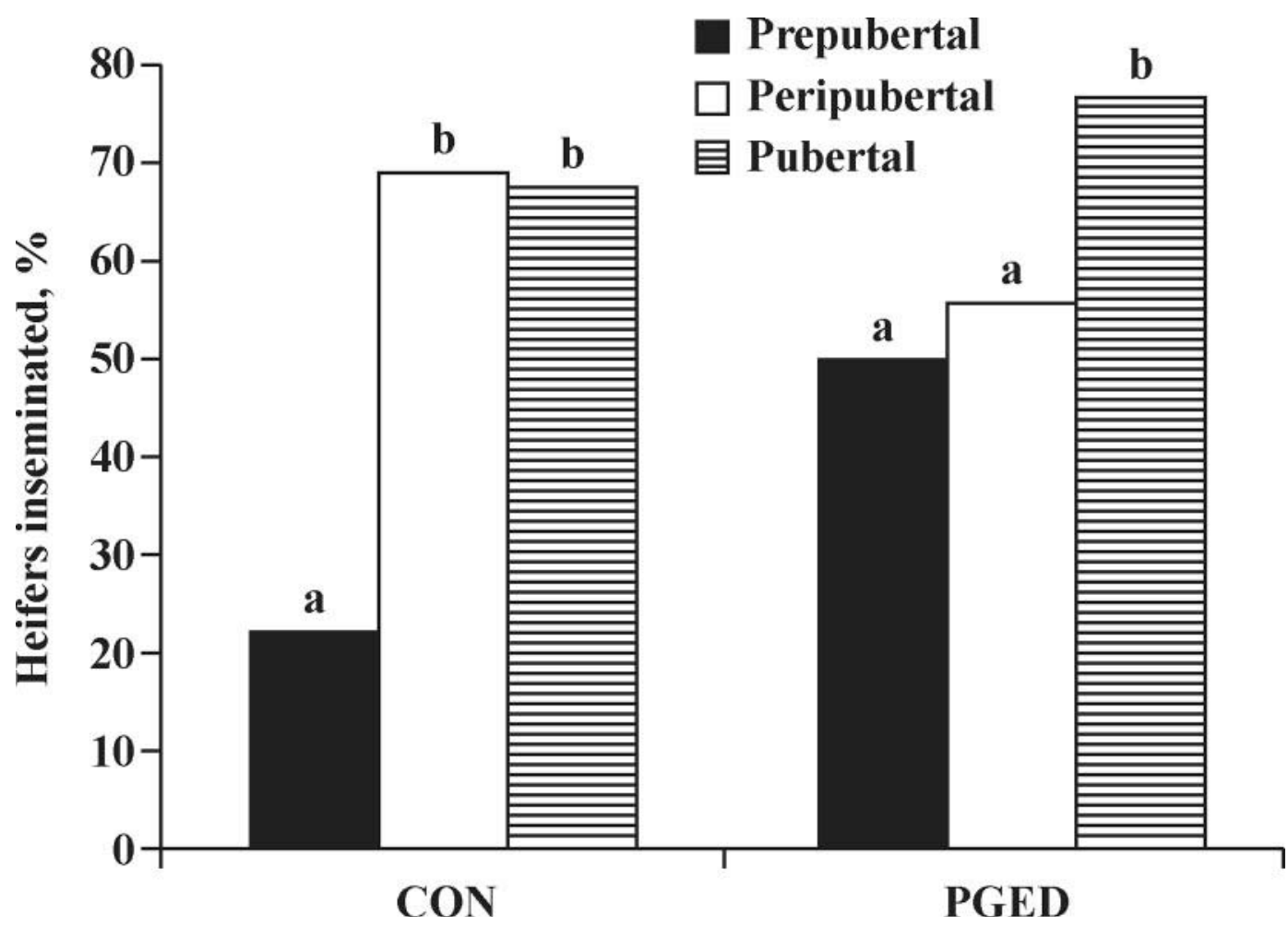

Figure 3. Proportion of CON (control) and PGED ( $\mathrm{PGF}_{2 \alpha}$-treated) heifers inseminated within $14 \mathrm{~d}$ of enrollment according to reproductive tract score (RTS). Effect of treatment $(P=0.35)$, RTS $(P<0.01)$, and the interaction between treatment and RTS $(P=0.08)$, ${ }^{\mathrm{a}, \mathrm{b}}$ Proportions having different letters within treatment differ $(P<0.05)$.

RTS did not $(P=0.28)$ affect the proportion of EDTAI and GTAI heifers displaying estrus 48 (prepubertal $=34.6$, peripubertal $=49.2$, pubertal $=56.7 \%$ ) and 72 (prepubertal $=69.2$, peripubertal $=82.5$, pubertal $=$ $82.3 \%)$ h after CIDR removal. The proportion of heifers inseminated on estrus $48(\mathrm{~A}=65.6, \mathrm{~B}=33.3 \%)$ and 72 $(\mathrm{A}=86.8, \mathrm{~B}=72.6 \%) \mathrm{h}$ after CIDR removal, however, was $(P<0.01)$ affected by AI technician. Furthermore, the interaction between $\mathrm{AI}$ technician and reproductive protocol affected the proportion of heifers observed in estrus $48 \mathrm{~h}$ after CIDR removal (technician A, EDTAI = 41.8 , GTAI $=84.5 \%$; technician $\mathrm{B}, \mathrm{EDTAI}=28.8$, GTAI $=44.8 \% ; P=0.03)$ and at $\mathrm{AI}$ (technician $\mathrm{A}, \mathrm{EDTAI}=$ 89.6, GTAI $=84.5 \%$; technician $\mathrm{B}, \mathrm{EDTAI}=83.6$, GTAI $=44.8 \% ; P=0.05)$, because as observed by technician $\mathrm{B}$, a smaller proportion of heifers in the GTAI treatment displayed estrus 48 and $72 \mathrm{~h}$ after CIDR removal.

The EDTAI and the GTAI treatments altered the estrous expression in such a way that within 3 and $2 \mathrm{~d}$ of CIDR removal, respectively, greater $(P<0.01)$ proportion of heifers displayed estrus compared with the proportion of heifers in the CON and PGED treatments that displayed estrus within $3 \mathrm{~d}$ of enrollment in the breeding program $(\mathrm{CON}=13.0, \mathrm{PGED}=48.2$, EDTAI $=86.4$, GTAI $=74.8 \%)$. The overall proportion of heifers displaying estrus during the breeding program was also affected by treatment $(P<0.01)$, and a smaller proportion of heifers in the GTAI treatment displayed estrus compared with the CON, PGED, and EDTAI treatments, which did not differ $(\mathrm{CON}=92.5$, $\mathrm{PGED}=92.7, \mathrm{EDTAI}=86.4, \mathrm{GTAI}=74.8 \%$ ).

\section{Pregnancy per Al and Pregnancy Rates}

The proportion of heifers diagnosed pregnant $32 \pm 3 \mathrm{~d}$ after AI was $(P<0.01)$ affected by treatment (Table 2$)$. Pregnancy per AI was not affected by RTS (prepubertal $=54.8$, peripubertal $=55.5$, pubertal $=59.9 \% ; P=$ $0.61)$ and $\mathrm{AI}$ technician $(\mathrm{A}=56.8, \mathrm{~B}=60.8 \%, P=0.36)$. The interval from enrollment to pregnancy among heifers that became pregnant was $(P<0.01)$ affected by treatment (Table 2), and PGED and EDTAI heifers had the shortest interval, whereas GTAI heifers had the longest. Reproductive tract score affected $(P<0.01)$ the interval to pregnancy, and pubertal heifers had the shortest interval and prepubertal heifers had the longest (prepubertal $=14.0 \pm 1.0$, peripubertal $=11.5$ \pm 0.6 , pubertal $=10.1 \pm 0.3 \mathrm{~d})$. Technician did not $(P=$ 0.66 ) affect the interval from enrollment to pregnancy $(\mathrm{A}=10.0 \pm 0.4, \mathrm{~B}=10.3 \pm 0.5 \mathrm{~d})$. 
Table 2. Reproductive performance of Holstein heifers submitted to different reproductive protocols

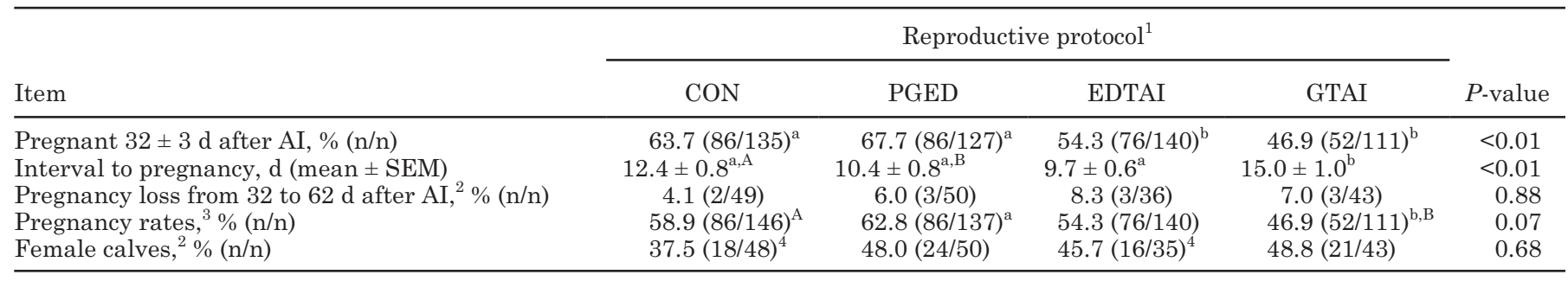

${ }^{\mathrm{a}, \mathrm{b}}$ Means having different superscript letters within a row differ $(P<0.05)$.

${ }^{\mathrm{A}, \mathrm{B}}$ Means having different superscript letters within a row differ $(P \leq 0.10)$.

${ }^{1} \mathrm{CON}=\mathrm{AI}$ upon estrous detection; $\mathrm{PGED}=\mathrm{PGF}_{2 \alpha}$ injection (Lutalyse Sterile Solution, dinoprost tromethramine sterile solution, $\mathrm{Pfizer}$ Animal Health, Kalamazoo, MI) on study d 0, estrous detection and AI from study d 0 to 14, heifers not inseminated by study d 14 received a second injection of $\mathrm{PGF}_{2 \alpha}$ and were $\mathrm{AI}$ upon detection of estrus for an additional $14 \mathrm{~d}$; EDTAI = insertion of a controlled internal drug-release (CIDR) insert (Eazi-Breed CIDR insert, Pfizer Animal Health) from study d 0 to 7 , at CIDR insert removal all heifers received an injection of $\mathrm{PGF}_{2 \mathrm{a}}$, $\mathrm{AI}$ upon detection of estrus from study d 7 to 10 , and those not inseminated by study d 10 received a $\mathrm{GnRH}$ injection (gonadorelin diacetate tetrahydrate, Cystorelin, Merial Ltd., Athens, GA) concomitant with fixed time AI; GTAI = GnRH injection on study d 0, on study d 6 all heifers received a CIDR insert and an injection of $\mathrm{GnRH}$ and $\mathrm{PGF}_{2 \alpha}$, at CIDR insert removal (study d 13) heifers received a PGF $2 a$ injection, and all heifers were inseminated at a fixed time concomitant with GnRH injection on study d 15.

${ }^{2} \mathrm{~A}$ subsample of heifers diagnosed pregnant $31 \pm 3 \mathrm{~d}$ after $\mathrm{AI}$ were reexamined $30 \mathrm{~d}$ later for evaluation of fetal survival and sex determination (CON, $\mathrm{n}=49$; PGED, $\mathrm{n}=50$; EDTAI, $\mathrm{n}=35$; GTAI, $\mathrm{n}=43$ ).

${ }^{3}$ Proportion of heifers pregnant at the end of the breeding period $(28 \mathrm{~d})$.

${ }^{4}$ Two heifers $(\mathrm{CON}=1$ and EDTAI $=1)$ had twin pregnancies, and fetal sex determination was not possible.

The rate at which CON and PGED heifers became pregnant was not $(P=0.11)$ different, and the mean $( \pm \mathrm{SEM})$ and median days to pregnancy for $\mathrm{CON}$ heifers were $15.6 \pm 0.6$ and $17 \mathrm{~d}$ and for PGED heifers were
$13.5 \pm 0.8$ and $16 \mathrm{~d}$, respectively. However, RTS tended $(P=0.10)$ to affect the rate at which heifers became pregnant (Figure 4). There was no $(P=0.25)$ effect of AI technician on the rate at which CON and PGED heifers

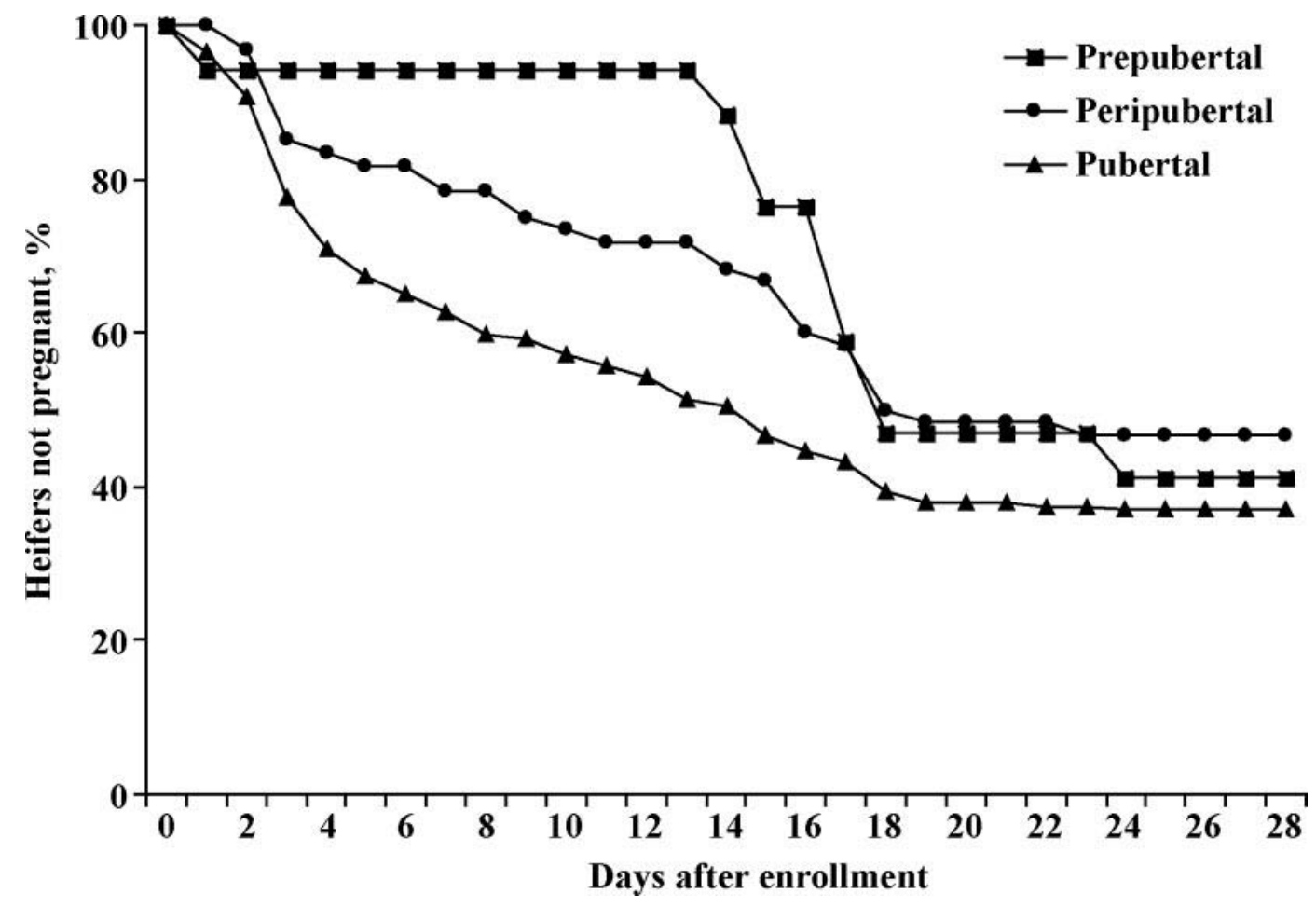

Figure 4. Rate at which CON (control) and PGED ( $\mathrm{PGF}_{2 a}$-treated) heifers with different reproductive tract scores (RTS) became pregnant after enrollment. Level of significance according the Cox proportional hazards ratio analysis was $P=0.10$ and according to the survival analysis was $P<0.03$. Mean $( \pm \mathrm{SEM})$ and median days from enrollment to conception were, respectively: prepubertal $=19.06 \pm 1.51$ and 18.00 ; peripubertal $=16.45 \pm 1.02$ and 18.50; and pubertal $=13.82 \pm 0.64$ and $15.00 \mathrm{~d}$. 


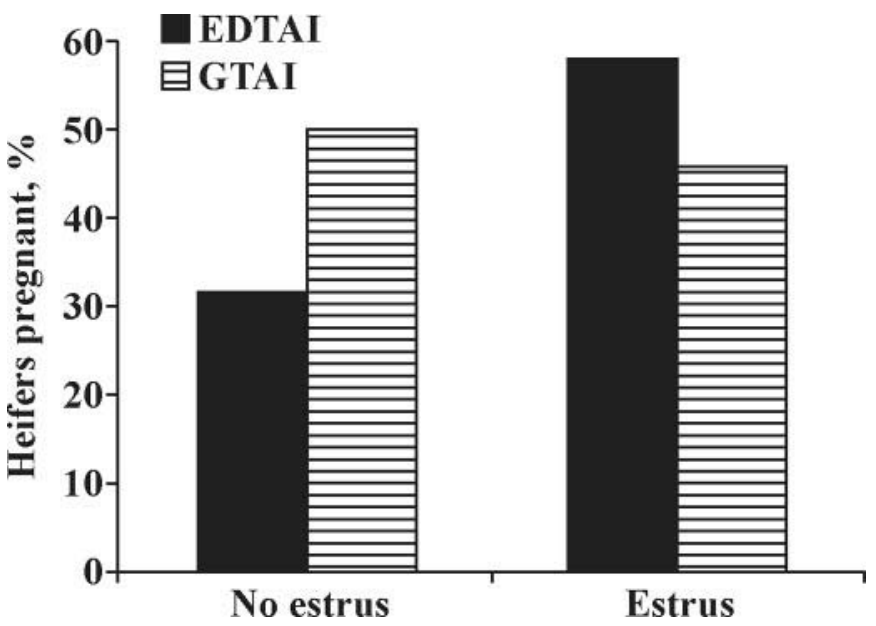

Figure 5. Proportion of EDTAI (estrous detection-timed AI) and GTAI (GnRH-timed AI) heifers diagnosed pregnant $35 \pm 3 \mathrm{~d}$ after AI according to estrous expression at AI. Effect of treatment $(P=0.68)$, effect of estrous expression $(P=0.18)$, and effect of the interaction between treatment and estrous expression $(P=0.07)$.

became pregnant, and the mean $( \pm \mathrm{SEM})$ intervals were $11.7 \pm 0.5$ and $15.7 \pm 0.8 \mathrm{~d}$ for technicians $\mathrm{A}$ and $\mathrm{B}$, respectively.

Among EDTAI and GTAI heifers, estrous expression at the time of AI did not $(P=0.18)$ affect the proportion of heifers diagnosed pregnant at $32 \pm 3 \mathrm{~d}$ after AI (no estrus $=42.6$, estrus $=52.9 \%)$. There was, however, a tendency $(P=0.07)$ for the interaction between estrous expression at the time of $\mathrm{AI}$ and treatment to affect the pregnancy per AI. Such an interaction was observed, because within the EDTAI treatment, pregnancy per AI was greater for heifers that displayed estrus at AI compared with those that did not display estrus (Figure 5). Actually, when only heifers that displayed estrus at AI were used in the analysis, a similar $(P$ $=0.31$ ) proportion of heifers in the EDTAI and CON treatments were diagnosed pregnant, and there was only a tendency $(P=0.09)$ for a greater proportion of PGED heifers to be diagnosed pregnant compared with EDTAI heifers $(\mathrm{CON}=58.9, \mathrm{PGED}=62.8$, and EDTAI $=57.9 \%)$. Regardless of estrous expression, however, GTAI heifers had smaller pregnancy per AI compared with the CON $(P=0.03)$ and PGED $(P<0.01)$ heifers.

The proportion of pregnant heifers at the end of the breeding program tended $(P=0.07)$ to be affected by reproductive protocol, because a smaller proportion of GTAI heifers were pregnant compared with PGED and CON heifers (Table 2). A similar proportion of CON, PGED, and EDTAI heifers was pregnant at the end of the breeding program (Table 2). Reproductive tract score (prepubertal $=53.5$, peripubertal $=54.6$, pubertal $=57.0 \% ; P=0.83)$ and $\mathrm{AI}$ technician $(\mathrm{A}=56.4, \mathrm{~B}=$
$55.9 \% ; P=0.92)$ did not affect the proportion of heifers pregnant at the end of the breeding program.

Treatment did not $(P=0.88)$ affect the proportion of heifers experiencing pregnancy loss from $32 \pm 3$ to $62 \pm$ $3 \mathrm{~d}$ of gestation (Table 2). Similarly, RTS (prepubertal $=15.4$, peripubertal $=9.4$, pubertal $=4.5 \% ; P=0.24)$ and AI technician $(\mathrm{A}=6.2, \mathrm{~B}=6.3 \% ; P=0.99)$ did not affect the incidence of pregnancy loss between $32 \pm$ 3 and $62 \pm 3 \mathrm{~d}$ of gestation. The proportion of heifers bearing female calves was not affected by treatment $(P$ $=0.68$; Table 2 ).

\section{Economic Outcomes}

Analysis of economic outcomes revealed that treatment affected $(P<0.01)$ the reproductive protocol cost, and $\mathrm{CON}$ treatment resulted in the smallest reproductive protocol cost followed by the PGED, EDTAI, and GTAI treatments, respectively (Table 3 ). Reproductive tract score affected $(P=0.01)$ the reproductive protocol cost, and pubertal heifers had a smaller reproductive protocol cost than prepubertal and peripubertal heifers (Table 3). This effect of reproductive tract score on reproductive protocol cost was observed because of an interaction between treatment and RTS $(P=0.02)$, because pubertal PGED heifers had smaller reproductive protocol cost than prepubertal and peripubertal PGED heifers (Table 3). This interaction was caused by the smaller $(P=0.01)$ number of $\mathrm{PGF}_{2 \alpha}$ injections that pubertal heifers received compared with prepubertal and peripubertal heifers (prepubertal $=1.7 \pm$ 0.2 , peripubertal $=1.4 \pm 0.1$, pubertal $=1.2 \pm 0.1 \mathrm{PGF}_{2 \alpha}$ injections). The reproductive protocol cost tended ( $P=$ $0.10)$ to be affected by AI technician $(\mathrm{A}=\$ 9.0 \pm 0.1, \mathrm{~B}$ $=\$ 9.1 \pm 0.1)$.

Treatment affected $(P=0.04)$ the rearing cost; GTAI heifers had the greatest rearing cost, whereas CON, PGED, and EDTAI heifers did not differ (Table 3). Reproductive tract score tended $(P=0.09)$ to affect rearing cost, and the interaction between treatment and RTS affected $(P=0.04)$ the rearing cost (Table 3). The technician of AI did not $(P=0.28)$ affect the rearing cost.

Similarly, the breeding program cost was affected ( $P$ $<0.01$ ) by treatment, because CON and PGED heifers had the smallest breeding program cost, GTAI heifers had the greatest, and EDTAI heifers had intermediary breeding program cost (Table 3). The breeding program cost tended $(P=0.08)$ to be affected by the RTS, because pubertal heifers tended to have a smaller breeding program cost than prepubertal heifers $(P=0.07)$. The interaction between treatment and RTS affected $(P=0.03)$ the breeding program cost, because pubertal PGED heifers had a smaller breeding program cost 
Table 3. Effect of reproductive protocols and reproductive tract score ${ }^{1}$ (RTS; 1, 2, or 3) on reproductive protocol cost (RPC), rearing cost (RRC), cost of the breeding program (CBP), and cost per pregnancy generated (CPG) expressed as means $( \pm \mathrm{SEM})$

\begin{tabular}{|c|c|c|c|c|c|c|c|c|c|c|c|c|c|c|c|}
\hline \multirow[b]{3}{*}{ Item } & \multicolumn{12}{|c|}{ Reproductive protocol $(\mathrm{RP})^{2}$} & & & \\
\hline & \multicolumn{3}{|c|}{$\mathrm{CON}$} & \multicolumn{3}{|c|}{ PGED } & \multicolumn{3}{|c|}{ EDTAI } & \multicolumn{3}{|c|}{ GTAI } & \multicolumn{3}{|c|}{$P$-value } \\
\hline & 1 & 2 & 3 & 1 & 2 & 3 & 1 & 2 & 3 & 1 & 2 & 3 & $\mathrm{RP}$ & RTS & $\mathrm{RP} \times \mathrm{RTS}$ \\
\hline $\begin{array}{l}\text { Percentage } \\
\text { (n) }\end{array}$ & $\begin{array}{l}6.2 \\
(9)\end{array}$ & $\begin{array}{l}17.8 \\
(26)\end{array}$ & $\begin{array}{l}76.0 \\
(111)\end{array}$ & $\begin{array}{l}5.8 \\
(8)\end{array}$ & $\begin{array}{l}24.8 \\
(34)\end{array}$ & $\begin{array}{l}69.3 \\
(95)\end{array}$ & $\begin{array}{c}12.1 \\
(17)\end{array}$ & $\begin{array}{l}30.0 \\
(42)\end{array}$ & $\begin{array}{l}57.9 \\
(81)\end{array}$ & $\begin{array}{l}8.1 \\
(9)\end{array}$ & $\begin{array}{l}17.1 \\
(19)\end{array}$ & $\begin{array}{l}74.8 \\
(83)\end{array}$ & $<0.01$ & - & - \\
\hline $\mathrm{RPC}, \$$ & $\begin{array}{r}1.2 \pm \\
0.2\end{array}$ & $\begin{array}{r}1.2 \pm \\
0.1\end{array}$ & $\begin{array}{r}1.2 \pm \\
0.1\end{array}$ & $\begin{array}{c}5.3 \pm \\
0.2^{\mathrm{a}}\end{array}$ & $\begin{array}{l}5.0 \pm \\
0.1^{\mathrm{a}}\end{array}$ & $\begin{array}{l}4.5 \pm \\
0.1^{b}\end{array}$ & $\begin{array}{c}11.7 \pm \\
0.2^{\mathrm{A}}\end{array}$ & $\begin{array}{r}11.4 \pm \\
0.1\end{array}$ & $\begin{array}{c}11.3 \pm \\
0.1^{\mathrm{B}}\end{array}$ & $\begin{array}{r}18.8 \pm \\
0.2\end{array}$ & $\begin{array}{r}18.8 \pm \\
0.2\end{array}$ & $\begin{array}{r}18.8 \pm \\
0.1\end{array}$ & $<0.01$ & 0.01 & 0.02 \\
\hline RRC, $\$$ & $\begin{array}{c}36.5 \pm \\
5.2^{\mathrm{A}}\end{array}$ & $\begin{array}{r}29.8 \pm \\
3.1\end{array}$ & $\begin{array}{c}28.3 \pm \\
1.5^{\mathrm{B}}\end{array}$ & $\begin{array}{r}33.4 \pm \\
5.5^{\mathrm{a}}\end{array}$ & $\begin{array}{r}31.5 \pm \\
2.7^{\mathrm{a}}\end{array}$ & $\begin{array}{c}21.8 \pm \\
1.6^{\mathrm{b}}\end{array}$ & $\begin{array}{r}30.4 \pm \\
3.8\end{array}$ & $\begin{array}{l}26.8 \pm \\
2.4^{\mathrm{A}}\end{array}$ & $\begin{array}{c}31.2 \pm \\
1.7^{\mathrm{B}}\end{array}$ & $\begin{array}{r}36.8 \pm \\
5.3\end{array}$ & $\begin{array}{r}38.4 \pm \\
3.6\end{array}$ & $\begin{array}{r}35.7 \pm \\
1.9\end{array}$ & 0.04 & 0.09 & 0.04 \\
\hline $\mathrm{CBP}, \$$ & $\begin{array}{r}36.8 \pm \\
5.2\end{array}$ & $\begin{array}{r}31.3 \pm \\
3.1\end{array}$ & $\begin{array}{r}29.5 \pm \\
1.5\end{array}$ & $\begin{array}{r}37.8 \pm \\
5.6^{\mathrm{a}}\end{array}$ & $\begin{array}{r}36.7 \pm \\
2.7^{\mathrm{a}}\end{array}$ & $\begin{array}{c}26.1 \pm \\
1.6^{\mathrm{b}}\end{array}$ & $\begin{array}{r}42.0 \pm \\
3.8\end{array}$ & $\begin{array}{c}38.1 \pm \\
2.4^{\mathrm{A}}\end{array}$ & $\begin{array}{c}42.5 \pm \\
1.7^{\mathrm{B}}\end{array}$ & $\begin{array}{r}55.5 \pm \\
5.2\end{array}$ & $\begin{array}{r}57.1 \pm \\
3.6\end{array}$ & $\begin{array}{r}54.4 \pm \\
1.7\end{array}$ & $<0.01$ & 0.08 & 0.03 \\
\hline $\mathrm{CPG}, \$$ & $\begin{array}{c}61.3 \pm \\
3.5^{\mathrm{a}}\end{array}$ & $\begin{array}{r}52.6 \pm \\
2.0^{\mathrm{b}}\end{array}$ & $\begin{array}{r}50.3 \pm \\
1.0^{\mathrm{b}}\end{array}$ & $\begin{array}{c}60.6 \pm \\
3.5^{\mathrm{a}}\end{array}$ & $\begin{array}{r}52.6 \pm \\
1.9^{b}\end{array}$ & $\begin{array}{c}44.3 \pm \\
1.0^{\mathrm{c}}\end{array}$ & $\begin{array}{r}75.9 \pm \\
2.6\end{array}$ & $\begin{array}{r}75.7 \pm \\
1.5\end{array}$ & $\begin{array}{r}75.7 \pm \\
1.2\end{array}$ & $\begin{array}{r}95.5 \pm \\
3.9\end{array}$ & $\begin{array}{r}95.5 \pm \\
3.0\end{array}$ & $\begin{array}{r}95.5 \pm \\
1.2\end{array}$ & $<0.01$ & $<0.01$ & 0.01 \\
\hline
\end{tabular}

${ }^{\mathrm{a}-\mathrm{c}}$ Within reproductive protocol and item, means with different superscripts differ $(P<0.05)$.

${ }^{\mathrm{A}, \mathrm{B}}$ Within reproductive protocol and item, means with different superscripts tended to differ $(P \leq 0.10)$.

${ }^{1}$ Reproductive tract score: 1 = prepubertal; 2 = peripubertal; and $3=$ pubertal.

${ }^{2} \mathrm{CON}=\mathrm{AI}$ upon estrous detection; PGED $=\mathrm{PGF}_{2 a}$ injection (Lutalyse Sterile Solution, dinoprost tromethramine sterile solution, Pfizer Animal Health, Kalamazoo, MI) on study d 0, estrous detection and AI from study d 0 to 14, heifers not inseminated by study d 14 received a second injection of PGF $2 a$ and were AI upon detection of estrus for an additional $14 \mathrm{~d}$; EDTAI = insertion of a controlled internal drug-release (CIDR) insert (Eazi-Breed CIDR insert, Pfizer Animal Health) from study d 0 to 7 , at CIDR insert nadorelin diacetate tetrahydrate, Cystorelin, Merial Ltd., Athens, GA) concomitant with fixed-time AI; GTAI = GnRH injection on study d 0, on study d 6 all heifers received a CIDR insert and an injection of GnRH and $\mathrm{PGF}_{2 \alpha}$, at CIDR insert removal (study d 13) heifers received a PGF $\mathrm{P}_{2 \alpha}$ injection, and all heifers were inseminated at a fixed time 을 concomitant with $\mathrm{GnRH}$ injection on study d 15. 
Table 4. Economic outcomes of different reproductive protocols according to 35 different scenarios

\begin{tabular}{lccccc}
\hline & \multicolumn{2}{c}{ Breeding program cost } & & \multicolumn{2}{c}{ Cost per pregnancy generated } \\
\cline { 2 - 3 } \cline { 5 - 6 } $\begin{array}{l}\text { Reproductive } \\
\text { protocol }^{1}\end{array}$ & Mean $( \pm$ SEM), $\$$ & Range, $\$$ & & Mean $( \pm$ SEM), $\$$ & Range, $\$$ \\
\hline CON & $29.77 \pm 0.26^{\mathrm{a}, \mathrm{A}}$ & $14.38,40.81$ & & $42.01 \pm 0.42^{\mathrm{a}}$ & $20.29,57.59$ \\
PGED & $29.16 \pm 0.26^{\mathrm{a}, \mathrm{B}}$ & $15.90,38.43$ & & $40.02 \pm 0.42^{\mathrm{b}}$ & $21.81,52.73$ \\
EDTAI & $34.20 \pm 0.26^{\mathrm{b}}$ & $21.86,42.85$ & & $49.84 \pm 0.42^{\mathrm{c}}$ & $31.86,62.44$ \\
GTAI & $55.43 \pm 0.26^{\mathrm{c}}$ & $35.22,68.08$ & & $84.89 \pm 0.42^{\mathrm{d}}$ & $53.93,104.27$ \\
\hline
\end{tabular}

${ }^{\mathrm{a}-\mathrm{d}}$ Means having different superscript letters within a column $\operatorname{differ}(P<0.05)$.

${ }^{\mathrm{A}, \mathrm{B}}$ Means having different superscript letters within a column tended to differ $(P \leq 0.10)$.

${ }^{1} \mathrm{CON}=\mathrm{AI}$ upon estrous detection; PGED $=\mathrm{PGF}_{2 \alpha}$ injection (Lutalyse Sterile Solution, dinoprost tromethramine sterile solution, Pfizer Animal Health, Kalamazoo, MI) on study d 0, estrous detection and AI from study d 0 to 14 , heifers not inseminated by study d 14 received a second injection of $\mathrm{PGF}_{2 \alpha}$ and were AI upon detection of estrus for an additional $14 \mathrm{~d}$; EDTAI = insertion of a controlled internal drug-release (CIDR) insert (Eazi-Breed CIDR insert, Pfizer Animal Health) from study d 0 to 7, at CIDR insert removal all heifers received an injection of $\mathrm{PGF}_{2 \alpha}$, $\mathrm{AI}$ upon detection of estrus from study $\mathrm{d} 7$ to 10 , and those not inseminated by study d 10 received a GnRH injection (gonadorelin diacetate tetrahydrate, Cystorelin, Merial Ltd., Athens, GA) concomitant with fixed-time AI; GTAI $=$ GnRH injection on study d 0, on study d 6 all heifers received a CIDR insert and an injection of $\mathrm{GnRH}$ and $\mathrm{PGF}_{2 a}$, at CIDR insert removal (study d 13) heifers received a $\mathrm{PGF}_{2 \mathrm{a}}$ injection, and all heifers were inseminated at a fixed time concomitant with GnRH injection on study d 15.

than prepubertal and peripubertal heifers (Table 3). Technician did not $(P=0.44)$ affect the breeding program cost.

Finally, treatment $(P<0.01)$, RTS $(P<0.01)$, and the interaction between treatment and RTS $(P<0.01)$ affected cost per pregnancy generated (Table 3). Such an interaction was observed, because peripubertal and pubertal CON heifers had the smallest cost per pregnancy generated, but within the PGED treatment, pubertal heifers had the smallest cost per pregnancy and prepubertal heifers had the largest, whereas peripubertal heifers had intermediary cost per pregnancy generated (Table 3).

According to the 35 different scenarios evaluated, the mean breeding program costs of the CON and PGED treatments were the smallest and that of the GTAI treatment was the greatest (Table 4). However, PGED treatment resulted in the smallest mean cost per pregnancy generated according to the different scenarios evaluated, followed by the CON, EDTAI, and GTAI treatments, respectively (Table 4).

\section{DISCUSSION}

Efficient and accurate detection of estrus are fundamental for successful reproductive management when no fixed-time AI protocols are implemented (Heersche and Nebel, 1994). The proportion of CON and PGED heifers inseminated during the first 14 and $28 \mathrm{~d}$ of the breeding program was not different, and it was similar to that described in previous studies (Schilling et al., 1982; Kaim et al., 1990; Chebel et al., 2007). However, PGED heifers were inseminated at a faster rate than $\mathrm{CON}$ heifers. Injection of $\mathrm{PGF}_{2 \alpha}$ causes luteolysis of $\mathrm{CL}$ present and allows heifers to express estrus because of the reduced progesterone concentration, whereas CON heifers responded to endogenous secretion of $\mathrm{PGF}_{2 \alpha}$ for spontaneous luteolysis before estrus. This resulted in a shorter interval to AI for PGED heifers compared with CON heifers. It is interesting to note that the interval from enrollment to AI was also shorter for EDTAI heifers compared with CON heifers. This study was conducted during the fall and winter. Although heat stress had no effect on estrous detection rate and conception rates according to a study in Idaho, (Chebel et al., 2007) in another study in Florida, heat stress reduced conception rates in nulliparous heifers (Donovan et al., 2003). Extreme heat stress could affect estrous expression by compromising viability of granulosa and thecal cells and reducing concentrations of estradiol. On the other hand, situations of extreme cold stress have been demonstrated to affect estrous detection rate (Chebel et al., 2007), which could be the result of increased energy needs with no concurrent increase in feed intake, resulting in negative energy balance and postponed onset of puberty and increased incidence of anovular condition. Therefore, in situations of extreme heat or cold stress, CON and PGED treatments could have resulted in smaller estrous detection rates and consequently smaller pregnancy rates, which could have ultimately affected the economic outcomes.

A greater proportion of pubertal heifers was inseminated within $14 \mathrm{~d}$ of enrollment, and these heifers had a shorter interval to AI than prepubertal and peripubertal heifers. These differences were observed mainly because treatment of pubertal heifers with $\mathrm{PGF}_{2 \alpha}$ in the PGED treatment resulted in shorter interval from enrollment to AI and a greater proportion of heifers 
inseminated within $14 \mathrm{~d}$ of enrollment compared with prepubertal and peripubertal heifers. Heifers classified as pubertal $(\mathrm{RTS}=3)$ either had a large follicle and no CL with uterine tone, characteristics of proestrus, or had a palpable CL, characteristic of diestrus. Following luteolysis, the occurrence of estrus is dependent on the stage of development of the follicles present in the ovaries. Therefore, it was expected that pubertal PGED heifers would have earlier onset of estrus because of induced luteolysis by the exogenous $\mathrm{PGF}_{2 \alpha}$ and presence of larger follicles. It is interesting, however, that no difference existed in the interval from enrollment to $\mathrm{AI}$ for CON heifers that were classified as peripubertal and pubertal. This is an indication that either peripubertal CON heifers were closer to onset of puberty than expected or that the distinction between peripubertal and pubertal heifers was not accurate. The onset of puberty in heifers is positively correlated with body weight, and in Holstein heifers, it occurs at approximately 250 to $300 \mathrm{~kg}$ (Bailey and Murphy, 1999; Looper and Bethard, 2000). Although body weight affects estrous detection rates (Chebel et al., 2007) and BCS is an indirect measure of body weight, in the present study, BCS did not affect RTS or reproductive outcomes.

In the current study, EDTAI heifers were allowed to be inseminated on estrus for $72 \mathrm{~h}$, and those not inseminated received TAI concurrent with GnRH. It is interesting to note that $85.5 \%$ of EDTAI heifers displayed signs of estrus within $72 \mathrm{~h}$ of CIDR removal, and the proportion of CON and PGED heifers displaying estrus over a 28 -d period was 92.2 and $90.9 \%$, respectively. Lucy et al. (2001) had demonstrated that the proportion of heifers inseminated after a 31-d breeding program was not different for those synchronized with CIDR insert and $\mathrm{PGF}_{2 \alpha}$ or $\mathrm{PGF}_{2 \alpha}$ alone. The use of CIDR inserts results in tighter synchrony of estrus after its withdrawal, because occurrence of estrus and ovulation is inhibited in animals that have spontaneous luteolysis during treatment (Chenault et al., 2003; El-Zarkouny et al., 2004; Chebel et al., 2006). A smaller proportion of EDTAI heifers became pregnant after AI compared with PGED heifers. Lucy et al. (2001) demonstrated no deleterious effect of synchronization with CIDR insert and $\mathrm{PGF}_{2 \alpha}$ on fertility of dairy heifers. In the current study, however, heifers that did not display signs of estrus by $72 \mathrm{~h}$ after CIDR removal received fixed-time $\mathrm{AI}$ concurrent with a GnRH injection. It is possible that some of the EDTAI heifers that did not display signs of estrus were anovular, a condition that has been related to reduced estrous expression and fertility in lactating dairy cows (Cerri et al., 2004; Santos et al., 2004; Chebel et al., 2006), or were not synchronized properly. Actually, estrous expression at the time of AI was related to fertility of EDTAI heifers, and when only heifers that displayed signs of estrus at the time of AI were evaluated, the proportion of EDTAI heifers that became pregnant was similar to CON heifers and only slightly smaller than PGED heifers. Nonetheless, because $100 \%$ of heifers in the EDTAI treatment were inseminated, the overall proportion of heifers pregnant at the end of the breeding program was not different for the EDTAI treatment compared with the CON and PGED treatments. Therefore, the EDTAI treatment used in the current study may be a good alternative when a large number of heifers has to be inseminated in a short period of time.

The proportion of GTAI heifers that became pregnant after AI was significantly smaller than CON and PGED heifers. Previous studies have demonstrated that dairy heifers inseminated at fixed time after the completion of ovulation synchronization protocols have smaller conception rates than heifers inseminated on detection of spontaneous estrus or $\mathrm{PGF}_{2 \mathrm{a}}$-induced estrus (Pursley et al., 1997; Tenhagen et al., 2005). The compromised pregnancy per AI of heifers submitted to fixed-time AI following ovulation synchronization protocols may be related to their pattern of follicular development, because nearly $50 \%$ of dairy heifers have 3 or more follicular waves, making synchronization of follicular growth and ovulation more challenging (Sartori et al., 2001). In a previous study, Stevenson et al. (2006) demonstrated that approximately $55 \%$ of dairy heifers presynchronized with a GnRH injection 6 $\mathrm{d}$ before the initiation of the ovulation synchronization protocol ovulated in response to the first $\mathrm{GnRH}$ injection of the protocol. The lack of greater synchronization of the estrous cycle after the first injection of $\mathrm{GnRH}$ of the synchronization protocol may result in ovulation of an aged follicle and oocyte at the end of the synchronization protocol (Stock and Fortune, 1993; Cerri et al., 2005) or spontaneous luteolysis and display of estrus before the conclusion of the synchronization protocol (Schmitt et al., 1996; Rivera et al., 2004), compromising fertility of heifers submitted to TAI.

The pattern of estrous expression of GTAI heifers, however, was distinct from that of EDTAI heifers. Within $48 \mathrm{~h}$ after CIDR removal, $74.3 \%$ of GTAI heifers displayed estrus, whereas only $35.0 \%$ of EDTAI heifers did so. The overall proportion of heifers displaying estrus at the time of insemination, however, was smaller for the GTAI treatment, because EDTAI heifers were allowed an additional $24 \mathrm{~h}$ for estrous expression before insemination at a fixed time. The growth of the ovulatory follicles in the presence of low concentrations of progesterone in beef cows and dairy heifers has resulted in a shorter interval from $\mathrm{PGF}_{2 \alpha}$ treatment to estrus and ovulation (Stegner et al., 2004; Stevenson et al., 2006). Therefore, it is possible that GTAI heifers 
had lower concentrations of progesterone during CIDR treatment because of the initial $\mathrm{PGF}_{2 \mathrm{a}}$ injection, resulting in faster growth of the ovulatory follicle and shorter interval to estrus and ovulation in comparison to EDTAI heifers. Furthermore, although the pregnancy per AI for EDTAI heifers that displayed estrus was nearly 25 percentage points greater than those that did not express estrus, there was no difference in pregnancy per AI for GTAI heifers that did or did not express estrus. This is a strong indication that the synchronization protocol used in the GTAI treatment was able to synchronize the estrous cycle and ovulation of heifers and that, although overall pregnancy per AI was smaller in GTAI heifers than the CON and PGED heifers, GTAI heifers could be inseminated without expressing estrus with no further detrimental effect on fertility.

The overall proportion of heifers pregnant at the end of the breeding program was smaller for GTAI treatment compared with CON and PGED treatments, even though $100 \%$ of GTAI heifers were inseminated and nearly $10 \%$ of CON and PGED heifers remained noninseminated by study d 28. This was because GTAI heifers had significantly smaller pregnancy per AI than CON and PGED heifers. Such a decrease in fertility of heifers submitted to fixed-time AI has been reported by other authors (Pursley et al., 1997; Tenhagen et al., 2005), and the GTAI protocol was not able to overcome it. Nonetheless, a similar proportion of EDTAI heifers were pregnant at the end of the breeding program compared with CON and PGED heifers, despite the former having smaller pregnancy per AI. This could be the result of the insemination of $100 \%$ of EDTAI heifers; however, it is also possible that a difference in the proportion of heifers pregnant at the end of the breeding program was not detected because of the relatively small number of heifers used.

The reproductive tract score did not affect pregnancy per $\mathrm{AI}$ and the proportion of heifers pregnant at the end of the breeding program. In contrast, pubertal heifers became pregnant faster than prepubertal and peripubertal heifers, and their median interval from enrollment to conception was 3.0 to $3.5 \mathrm{~d}$ shorter, respectively. Reproductive tract scoring is a method to evaluate pubertal status of heifers that has been used in the beef industry. The system is based on a 5 -point scale, where heifers classified with a RTS $=1$ to 2 are considered prepubertal, those with RTS $=3$ are considered peripubertal, and heifers with RTS $=4$ and 5 are considered pubertal (Andersen et al. 1991). Heifers with toneless uterine horns and small ovaries with follicles $<5 \mathrm{~mm}$ or follicles between 5 and $8 \mathrm{~mm}$ in diameter are classified RTS $=1$ and 2, respectively (prepubertal in the present study). Heifers with slight uterine tone and follicles between 8 and $10 \mathrm{~mm}$ in diameter are considered on the verge of puberty and are classified with RTS $=3$ (peripubertal in the current study). Finally, those heifers with considerable uterine tone and follicles $\geq 10 \mathrm{~mm}$ in diameter receive a RTS of 4 , whereas heifers that present a CL at the time of examination are classified as RTS $=5$ (pubertal in the present study). Rosenkrans and Hardin (2003) evaluated the accuracy of the RTS system in determining pubertal status of beef heifers as compared with serum progesterone concentrations from 2 blood samples collected $10 \mathrm{~d}$ apart and ultrasonography of the ovaries. The level of agreement between the RTS system and ultrasonography-progesterone concentrations in differentiating prepubertal from pubertal status was significantly high (72\%). Furthermore, in other studies, heifers with RTS $=1$ had a pregnancy rate 41 to $58 \%$ smaller than heifers with RTS $=4$ and 5 , and heifers with RTS $=3$ to 5 conceived on average $10 \mathrm{~d}$ earlier than heifers with RTS $=1$ and 2 (Andersen et al., 1991). Furthermore, LeFever and Odde (1986) observed that heifers with RTS $\geq 4$ had an estrous detection rate greater than $90 \%$ and pregnancy per AI greater than $50 \%$, whereas heifers with RTS $\leq 3$ had an estrous detection rate smaller than $80 \%$ and pregnancy per AI smaller than $37 \%$. Therefore, it is reasonable to conclude that the RTS system used in the current study was useful in estimating puberty status and provided similar results regarding its effects on fertility compared with previous reports.

The cost of the reproductive protocols was significantly greater for GTAI and EDTAI heifers. This result was expected, because, although these treatments reduced the need for estrous detection, they also required more drugs and more frequent handling of the animals for their administration. The rearing cost of the different reproductive protocols was dependent upon the rate at which heifers became pregnant and the overall proportion of heifers pregnant at the end of the study period. Therefore, because PGED heifers became pregnant at a faster rate, they had the smallest rearing cost. The breeding program cost was significantly smaller for the CON and PGED treatments, because they resulted in the smallest reproductive protocol cost and rearing cost and because a greater proportion of these heifers became pregnant at the end of the breeding program compared with the GTAI treatment. It is interesting to note that although PGED heifers had a smaller interval to insemination compared with the CON heifers, they had a similar cost per pregnancy. The cost per pregnancy generated was significantly smaller for CON and PGED heifers compared with EDTAI and GTAI heifers. According to the different scenarios evaluated, however, the smallest cost per pregnancy generated was for the PGED treatment, followed by the CON, 
EDTAI, and GTAI treatments, respectively. Therefore, it is clear that the use of $\mathrm{PGF}_{2 a}$ improved reproductive efficiency in such a manner that overcame the extra costs related to $\mathrm{PGF}_{2 \alpha}$ injections and animal handling.

The RTS also affected the economic outcomes evaluated. Such an effect was observed mostly because peripubertal and pubertal CON and PGED heifers had significantly smaller rearing cost, breeding program cost, and consequently smaller cost per pregnancy generated compared with prepubertal heifers. These differences could be accounted for by the greater insemination rates and faster rate of pregnancy in peripubertal and pubertal heifers. In the EDTAI and GTAI treatments, such differences were not evident because fixed-time AI was performed in all heifers.

\section{CONCLUSIONS}

The use of $\mathrm{PGF}_{2 \alpha}$ resulted in a faster rate of insemination of dairy heifers with no deleterious effects on fertility, which resulted in heifers becoming pregnant at a faster rate compared with heifers inseminated on detection of spontaneous signs of estrus. The use of a CIDR insert and $\mathrm{PGF}_{2 \alpha}$ resulted in tighter synchrony of estrus, and although the proportion of heifers that conceived after AI following this protocol was smaller than that of heifers inseminated on detection of spontaneous or $\mathrm{PGF}_{2 \mathrm{a}}$-induced estrus, the overall proportion of heifers pregnant at the end of the study period was not different. The TAI protocol (GTAI) resulted in an extended interval from enrollment to AI and conception, smaller pregnancy per AI, and a smaller proportion of heifers pregnant at the end of the breeding program, and this resulted in greater cost per pregnancy generated. Because the reproductive protocol based on AI on detection of spontaneous or $\mathrm{PGF}_{2 \alpha}$-induced estrus resulted in reduced reproductive protocol costs and rearing costs, respectively, they also resulted in the smallest breeding program cost and cost per pregnancy generated. When different scenarios were evaluated, the PGED protocol resulted in the smallest cost per pregnancy. Finally, heifers with more mature reproductive tract (pubertal) had greater estrous detection rate and became pregnant at a faster rate, which also resulted in smaller cost per pregnancy. Therefore, using $\mathrm{PGF}_{2 \mathrm{a}}$-based synchronization protocols for dairy heifers resulted in the best reproductive efficiency and economic outcomes.

\section{REFERENCES}

Andersen, K. J., D. G. LeFever, J. S. Brinks, and K. G. Odde. 1991. The use of reproductive tract scoring in beef heifers. Agric. Practice 12:19-26.
Bailey, T., and J. M. Murphy. 1999. Monitoring dairy heifer growth. 404-286. Virginia Cooperative Extension, Virginia State University, Petersburg.

Cerri, R. L. A., H. M. Rutigliano, R. G. S. Bruno, R. C. Chebel, and J. E. P. Santos. 2005. Effect of artificial insemination (AI) protocol on fertilization and embryo quality in high-producing dairy cows. J. Dairy Sci. 88(Suppl. 1):86. (Abstr.)

Cerri, R. L., J. E. Santos, S. O. Juchem, K. N. Galvão, and R. C. Chebel. 2004. Timed artificial insemination with estradiol cypionate or insemination at estrus in high-producing dairy cows. J. Dairy Sci. 87:3704-3715.

Chebel, R. C., F. A. Braga, and J. C. Dalton. 2007. Factors affecting reproductive performance of dairy heifers. Anim. Reprod. Sci. 101:208-224.

Chebel, R. C., J. E. P. Santos, R. L. A. Cerri, H. M. Rutigliano, and R. G. S. Bruno. 2006. Reproductive performance of lactating dairy cows following progesterone insert based presynchronization and resynchronization protocols. J. Dairy Sci. 89:4205-4219.

Chenault, J. R., J. F. Boucher, K. J. Dame, J. A. Meyer, and S. L. WoodFollis. 2003. Intravaginal progesterone insert to synchronize return to estrus of previously inseminated dairy cows. J. Dairy Sci. 86:2039-2049.

Donovan, G. A., F. L. Bennett, and F. S. Springer. 2003. Factors associated with first service conception in artificially inseminated nulliparous Holstein heifers. Theriogenology 60:67-75.

El-Zarkouny, S. Z., J. A. Cartmill, B. A. Hensley, and J. S. Stevenson. 2004. Pregnancy in dairy cows after synchronized ovulation regimens with or without presynchronization and progesterone. J. Dairy Sci. 87:1024-1037.

Ettema, J. F., and J. E. Santos. 2004. Impact of age at calving on lactation, reproduction, health, and income in first-parity Holsteins on commercial farms. J. Dairy Sci. 87:2730-2742.

Ferguson, J. D., D. T. Galligan, and N. Thomsen. 1994. Principal descriptors of body condition score in Holstein cows. J. Dairy Sci. 77:2695-2703.

Gabler, M. T., P. R. Tozer, and A. J. Heinrichs. 2000. Development of a cost analysis spreadsheet for calculating the costs to raise a replacement dairy heifer. J. Dairy Sci. 83:1104-1109.

Heersche, G. Jr, and R. L. Nebel. 1994. Measuring efficiency and accuracy of detection of estrus. J. Dairy Sci. 77:2754-2761.

Jochle, W., D. Kuzmanov, and J. Vujosevic. 1982. Estrous cycle synchronization in dairy heifers with the prostaglandin analog alfaprostol (I). Theriogenology 18:215-225.

Kaim, M., M. Rosenberg, and Y. Folman. 1990. Management of reproduction in dairy heifers based on the synchronization of estrous cycles. Theriogenology 34:537-547.

Keown, J. F., and R. W. Everett. 1986. Effect of days carried calf, days dry, and weight of first calf heifers on yield. J. Dairy Sci. 69:1891-1896.

LeFever, D. G., and K. G. Odde. 1986. Predicting reproductive performance in beef heifers by reproductive tract evaluation before breeding. Pages 13-15 in Colorado State University Beef Program Report. Colorado State University, Fort Collins.

Looper, M., G. Bethard. 2000. Management considerations in Holstein heifer development. Guide B-118. Cooperative Extension Service, New Mexico State University, Las Cruces.

Losinger, W. C., and A. J. Heinrichs. 1997. An analysis of age and body weight at first calving for Holstein in the United States. Prev. Vet. Med. 32:193-205.

Lucy, M. C., H. J. Billings, W. R. Butler, L. R. Ehnis, M. J. Fields, D. J. Kesler, J. E. Kinder, R. C. Mattos, R. E. Short, W. W. Thatcher, R. P. Wettemann, J. V. Yelich, and H. D. Hafs. 2001. Efficacy of an intravaginal progesterone insert and an injection of $\mathrm{PGF}_{2 \alpha}$ for synchronizing estrus and shortening the interval to pregnancy in postpartum beef cows, peripubertal beef heifers, and dairy heifers. J. Anim. Sci. 79:982-995.

NRC. 2001. Nutrient Requirements of Dairy Cattle. 7th ed. Natl. Acad. Press, Washington, DC.

Pursley, J. R., M. C. Wiltbank, J. S. Stevenson, J. S. Ottobre, H. A. Garverick, and L. L. Anderson. 1997. Pregnancy rates per artificial insemination for cows and heifers inseminated at a 
synchronized ovulation or synchronized estrus. J. Dairy Sci. 80:295-300.

Rivera, H., H. Lopez, and P. M. Fricke. 2004. Fertility of Holstein dairy heifers after synchronization of ovulation and timed AI or AI after removed tail chalk. J. Dairy Sci. 87:2051-2061.

Rosenkrans, K. S., and D. K. Hardin. 2003. Repeatability and accuracy of reproductive tract scoring to determine pubertal status in beef heifers. Theriogenology 59:1087-1092.

Santos, J. E., S. O. Juchem, R. L. Cerri, K. N. Galvão, R. C. Chebel, W. W. Thatcher, C. S. Dei, and C. R. Bilby. 2004. Effect of bST and reproductive management on reproductive performance of Holstein dairy cows. J. Dairy Sci. 87:868-881.

Sartori, R., P. M. Fricke, J. C. Ferreira, O. J. Ginther, and M. C Wiltbank. 2001. Follicular deviation and acquisition of ovulatory capacity in bovine follicles. Biol. Reprod. 65:1403-1409.

Schilling, E., W. Jochle, and D. Smidt. 1982. Estrous cycle synchronization in dairy heifers with the prostaglandin analog alfaprostol (II). Theriogenology 18:413-422.

Schmitt, E. J., T. Diaz, C. M. Barros, R. L. de la Sota, M. Drost, E. W. Fredriksson, C. R. Staples, R. Thorner, and W. W. Thatcher. 1996. Differential response of the luteal phase and fertility in cattle following ovulation of the first-wave follicle with human chorionic gonadotropin or an agonist of gonadotropin-releasing hormone. J. Anim. Sci. 74:1074-1083.

Stegner, J. E., F. N. Kojima, J. F. Bader, M. C. Lucy, M. R. Ellersieck, M. F. Smith, and D. J. Patterson. 2004. Follicular dynamics and steroid profiles in cows during and after treatment with progestin-based protocols for synchronization of estrus. J. Anim. Sci. 82:1022-1028.

Stevenson, J. L., R. C. Chebel, J. C. Dalton, J. E. P. Santos, R. Sartori, and A. Ahmadzadeh. 2006. Effect of synchronization protocols on follicular development of dairy heifers. J. Dairy Sci. 89(Suppl. 1):150. (Abstr.)

Stock, A. E., and J. E. Fortune. 1993. Ovarian follicular dominance in cattle: Relationship between prolonged growth of the ovulatory follicle and endocrine parameters. Endocrinology 132:11081114.

Tanabe, T. Y., and R. C. Hann. 1984. Synchronized estrus and subsequent conception in dairy heifers treated with prostaglandin $\mathrm{F}_{2}$ a. I. Influence of stage of cycle at treatment. J. Anim. Sci. 58:805-811.

Tenhagen, B. A., S. Kuchenbuch, and W. Heuwieser. 2005. Timing of ovulation and fertility of heifers after synchronization of oestrus with GnRH and prostaglandin $\mathrm{F}(2 \alpha)$. Reprod. Domest. Anim. 40:62-67.

Vasconcelos, J. L., R. W. Silcox, G. J. Rosa, J. R. Pursley, and M. C. Wiltbank. 1999. Synchronization rate, size of the ovulatory follicle, and pregnancy rate after synchronization of ovulation beginning on different days of the estrous cycle in lactating dairy cows. Theriogenology 52:1067-1078. 